\title{
Programa Culturando: uma ponte entre Academia e Sociedade
}

\author{
Marina Luciana Abreu de Melo ${ }^{1}$ \\ Eduardo Vieira Guimarães ${ }^{2}$ \\ Ernani Clarete da Silva ${ }^{3}$
}

Resumo: No Brasil, os direitos sociais garantidos por lei são frequentemente violados. A consequente desigualdade social é refletida na restrição ao acesso de bens culturais, bem como à educação e à capacitação profissional. Os objetivos do Programa de Extensão Culturando foram: I - promover a Cultura, a Educação e a Capacitação profissional como instrumentos para a Extensão universitária e II - construir uma ponte social para aproximar o campus Sete Lagoas da Universidade Federal de São João del-Rei das comunidades em seu entorno. Para isso, optou-se por uma metodologia baseada na pesquisa participante, em que o público-alvo das ações é considerado coprodutor do conhecimento. O Programa adotou um formato operacional subdividido em diferentes frentes, condicionadas pela demanda da população assistida. A parceria com a associação comunitária Projeto Local de Envolvimento Comunitário (PLEC) foi ampliada e consolidada, viabilizando a realização de oficinas educacionais e de capacitação direcionadas à população adjacente ao campus, além de um evento anual (Integrando), com diversas ações concentradas ao longo de um dia. Em dois anos de atividade (2017-2018), foram realizadas nove oficinas, quatro apresentações musicais e duas edições do Integrando. Contabilizou-se a participação de 715 pessoas, entre membros da comunidade acadêmica e do público-alvo. Por todas as ações desempenhadas, considera-se que o Programa Culturando atende aos princípios da Extensão universitária e constitui uma ponte entre a Universidade e as comunidades em seu entorno.

Palavras chave: Capacitação, Cultura, Educação, Oficinas.

\section{Culturando Program: a bridge between Academy and Society}

Abstract: In Brazil, social rights guaranteed by law are often violated. The resulting social inequality is reflected in the restriction on access to cultural goods, as well as to education and professional training. The objectives of the Culturando Program were: I - to promote Culture, Education and Professional training as instruments for University Extension and II - to build a social bridge between the Sete Lagoas campus of the Federal University of Sao Joao del-Rei (UFSJ-CSL) and its surrounding communities. For these purposes, a methodology based on the participant research was chosen, in which the target group of the actions is considered coproducer of the knowledge. The Program assumed an operational format subdivided into different fronts, which were conditioned by the assisted population's demand. The partnership with the community association Local Community Involvement Project (PLEC) was expanded and consolidated, making it possible to perform workshops to the campus' surrounding population, as well as an annual event (Integrando), with several actions concentrated throughout one day. In two years (2017-2018), nine sociocultural and training workshops, four musical presentations and two editions of the Integrando were performed. 715 people participated, among academics and the target group. For all actions done, it is

\footnotetext{
${ }^{1}$ Universidade de São Paulo (USP).

${ }^{2}$ Universidade Federal de São João del-Rei

${ }^{3}$ Universidade Federal de São João del-Rei
} 
considered that the Culturando Program meets the principles of the University Extension and constitutes a bridge between the University and its surrounding communities.

Keywords: Professional training, Culture, Education, Workshops.

\section{INTRODUÇÃO}

Os direitos sociais fundamentais foram consagrados no artigo $6^{\circ}$ da Constituição Federal Brasileira de 1988 (SILVA et al., 2018), conhecida como a "Constituição cidadã". Esse artigo assegura como direitos sociais "a educação, a saúde, a alimentação, o trabalho, a moradia, o transporte, o lazer, a segurança, a previdência social, a proteção à maternidade e à infância e a assistência aos desamparados". No entanto, em uma rápida avaliação da realidade socioeconômica dos brasileiros, em especial das crianças e dos jovens, constata-se a frequente violação desses direitos e a perpetuação da desigualdade social.

Essa desigualdade torna-se ainda mais ampla no acesso aos bens culturais. De acordo com pesquisa divulgada em 2010 pelo Instituto Brasileiro de Geografia e Estatística (IBGE), $10 \%$ da população mais rica do Brasil concentra $40 \%$ de todo o consumo cultural no país. Além disso, somente as regiões metropolitanas contribuem com $41 \%$ desse consumo. Na área de literatura, $73 \%$ dos livros estão concentrados em $16 \%$ da população. O diagnóstico ainda indica que $92 \%$ da população nunca entraram em um museu. Como se não bastasse, quase todos os brasileiros nunca frequentaram alguma exposição de arte, mais de $70 \%$ nunca assistiram a um espetáculo de dança e grande parte dos municípios não possui salas de cinema, teatro, museus e espaços culturais multiuso (UNESCO, 2017).

A área da Educação no Brasil também apresenta enormes desafios. De forma geral, os recursos do setor são mal aplicados, resultando em escolas sucateadas, educadores mal remunerados (DIAS, 2015) e alunos desmotivados. Se a Base Nacional Comum Curricular já apresenta grandes dificuldades para sua efetiva aplicação, a implantação da Política Nacional de Educação Ambiental (Lei 9.795/99) nas escolas brasileiras é uma realização ainda mais distante. Essas deficiências, por sua vez, se perpetuam ao longo de todo o sistema educacional, culminando no acesso restrito à capacitação profissional e ao Ensino Superior.

A Cultura e a Educação são elementos essenciais para o desenvolvimento humano, em todos os seus aspectos. Em seu sentido mais amplo, a palavra cultura diz respeito a toda riqueza e complexidade dos agrupamentos humanos e às características que, simultaneamente, os unem e os diferenciam (SANTOS, 2017). Já a educação é uma fração do modo de vida dos grupos sociais que a criam e recriam em sua sociedade (BRANDÃO, 2017). Diante dessas Revista Extensão em Foco, no 19, Jul./ Dez. (2019), p. 86 - 103. 
abordagens, é imprescindível que todos os cidadãos se comprometam com o papel estratégico da cultura e da educação enquanto agentes transformadores e transformados pela sociedade.

No contexto das universidades, o comprometimento com os aspectos sociais pode ser alcançado por meio da Extensão universitária. Essa expressão se refere a um processo educativo, cultural e científico que articula o ensino e a pesquisa de forma indissociável e viabiliza a relação transformadora entre Universidade e Sociedade (FORPROEX, 2012). Nesse sentido, ressalta-se a Extensão universitária enquanto uma forma de interação que deve existir entre a universidade e a comunidade em que está inserida, em uma espécie de ponte permanente entre a academia e os demais setores da sociedade (NUNES; SILVA, 2011).

Considerando o exposto, o objetivo com este trabalho foi promover o incentivo à Cultura, à Educação e à Capacitação profissional como instrumento para a Extensão universitária. Como fim último, buscou-se produzir um modelo bem-sucedido para a construção de uma ponte social entre o espaço acadêmico e as comunidades em seu entorno.

\section{METODOLOGIA}

Para a realização dos objetivos propostos, criou-se, em 2015, um Programa de Extensão, denominado Programa Culturando, sito no campus Sete Lagoas da Universidade Federal de São João del-Rei, UFSJ, Sete Lagoas, MG. O campus é adjacente a comunidades de elevado risco sociocultural, fomentando ações que visem transformar essa realidade. A metodologia do Programa baseou-se em modelos de pesquisa participante, em que os sujeitos da pesquisa são considerados coprodutores do conhecimento (STRECK, 2016). As propostas de intervenção para os anos de 2017 e 2018 foram organizadas nos seguintes eixos estruturais:

\section{Atividades Preparatórias:}

- dialogar com representantes das comunidades adjacentes à universidade, elaborando propostas a partir das principais demandas comunitárias;

- fortalecer as parcerias estabelecidas com as organizações comunitárias;

- dialogar com lideranças dos demais projetos de Extensão do campus, buscando fomentar parcerias para a realização de eventos de integração entre a universidade e as comunidades em seu entorno.

\section{Atividades Culturais:}

- executar oficinas socioeducativas para crianças e jovens que residem nas comunidades adjacentes ao campus;

Revista Extensão em Foco, no 19, Jul./ Dez. (2019), p. 86 - 103. 
- realizar apresentações artísticas dentro e fora do campus, a partir da criação de um grupo musical composto por membros do Programa;

- planejar, captar recursos humanos e materiais, coordenar e colaborar na realização de eventos de Extensão que envolvam a mobilização de toda a comunidade acadêmica.

\section{Atividades de Avaliação, Gestão e Divulgação:}

- realizar reuniões quinzenais com os membros do Programa, a fim de discutir o andamento das atividades e os desafios para sua execução;

- participar de reuniões promovidas por lideranças comunitárias, com o intuito de repassar e discutir com a comunidade as ações de intervenção;

- aplicar questionários e registrar o relato de participantes após a realização de oficinas, com o objetivo de avaliar o seu impacto e obter sugestões de melhorias;

- participar de eventos acadêmicos, visando promover a divulgação do Programa em âmbito local, regional e nacional;

- manter e atualizar endereços eletrônicos para contato e divulgação.

\section{RESULTADOS E DISCUSSÃO}

Durante os anos de 2017 e 2018, as atividades realizadas pelo Programa Culturando foram orientadas pelas demandas do público-alvo, identificadas em reuniões mensais com lideranças comunitárias. Por meio dessas reuniões, verificou-se a necessidade de ampliar as frentes de ação do Programa para além de práticas socioculturais, inserindo algumas atividades de capacitação profissional para jovens e adultos. Nesse mesmo período, foi consolidada a parceria com o Projeto Local de Envolvimento Comunitário (PLEC) e seus colaboradores. Essa associação comunitária, situada no Bairro Itapoã II e adjacente ao campus, oferece diversas atividades para crianças, jovens e mulheres residentes em seu entorno. O Programa também atuou em parceria com os demais projetos de Extensão da UFSJ-CSL, em ações que serão descritas a seguir.

\section{Oficinas socioeducativas}

\section{Oficina de brigadeiro}

A área geográfica na qual se situa o Campus da UFSJ em Sete Lagoas (UFSJ-CSL) possui elevada densidade demográfica e poucas oportunidades de emprego. Além disso, observa-se a restrição de políticas públicas que visem reverter esse contexto (PINHEIRO et Revista Extensão em Foco, no 19, Jul./ Dez. (2019), p. 86 - 103. 
al., 2017). Diante desses desafios, ressalta-se a importância de ações que gerem alternativas de renda para a população. Com esse propósito, alunas do curso de Engenharia de Alimentos e voluntárias do Programa Culturando promoveram, no dia 20 de abril de 2018, uma oficina de produção de brigadeiros especiais.

A atividade foi realizada na associação comunitária PLEC, sendo direcionada a meninas entre 10 a 14 anos, residentes no entorno da UFSJ-CSL e em situação de fragilidade econômica. Anteriormente à realização da oficina, um folheto com orientações sobre os procedimentos de higienização foi distribuído às participantes inscritas. Durante a atividade, foi notória a satisfação das meninas, que se refletiu nas respostas positivas ao questionário aplicado após a realização da oficina. Todas as participantes afirmaram que gostaram da atividade e que gostariam que mais iniciativas como essa fossem promovidas (Figura 1).

Figura 1 - Folheto de divulgação e orientações para a oficina de brigadeiro, registros durante a oficina e questionário aplicado aos participantes.

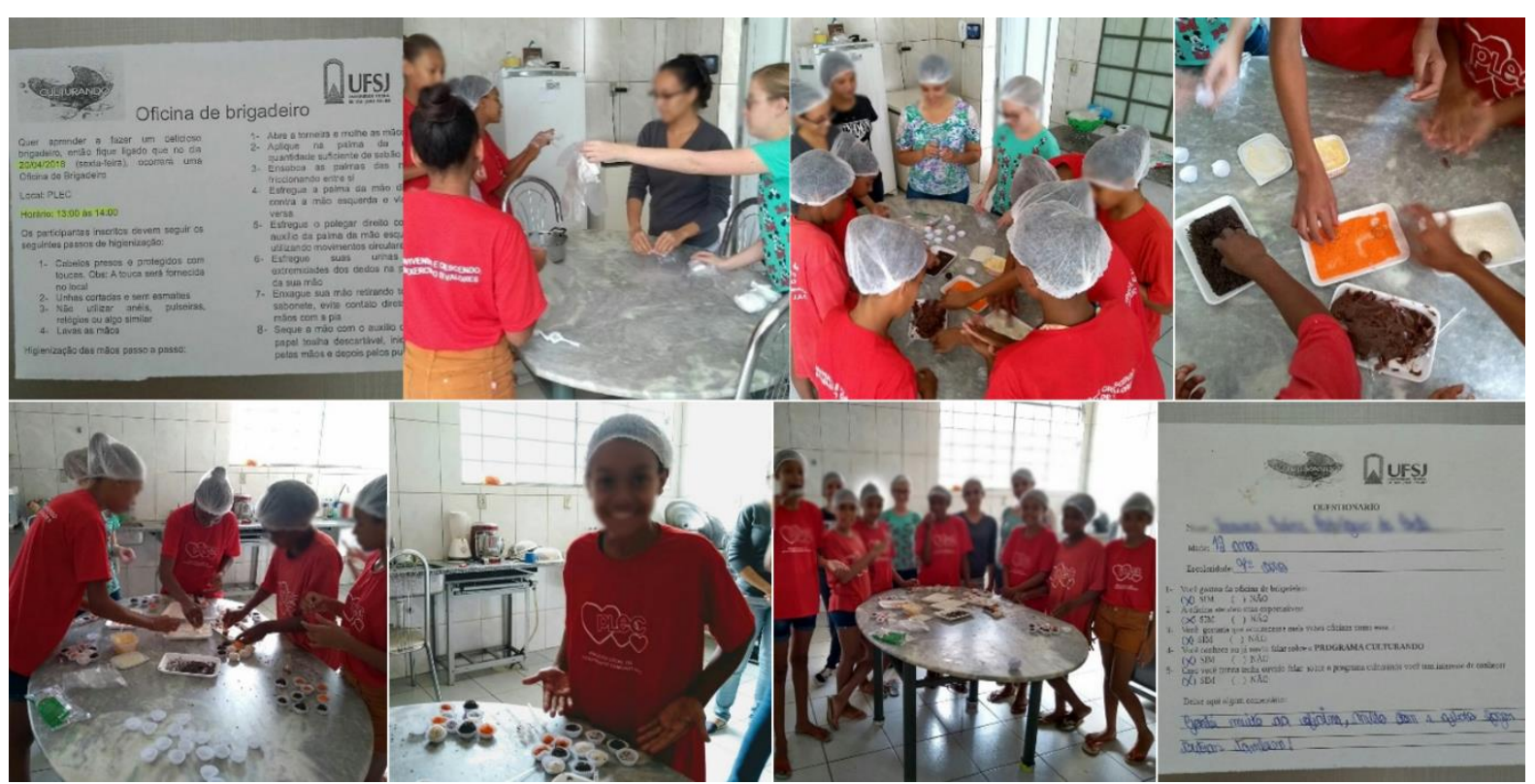

Fonte: arquivo pessoal.

Oficina de móveis recicláveis

Além da promoção de alternativas de renda, as frentes de ação do Programa Culturando incluem a educação e a conscientização ambiental, garantindo que as futuras gerações possam usufruir dos recursos naturais de forma sustentável. Segundo Dias e Guimarães (2015), é papel do meio acadêmico entender e iniciar um processo coletivo de conscientização, com o intuito de preparar a sociedade para viver melhor, por meio das próximas gerações.

Revista Extensão em Foco, no 19, Jul./ Dez. (2019), p. 86 - 103. 
Com esse objetivo, membros do Programa promoveram, em parceria com o Grupo Guayi de Agroecologia da UFSJ-CSL, uma oficina de fabricação de bancos de pneus e mesas de carretel com mosaico em cerâmica reutilizada. Membros do grupo Guayi se propuseram a ensinar a fabricação dos bancos, enquanto a produção das mesas foi designada aos membros do Programa Culturando.

A atividade foi realizada no dia 04 de maio de 2018, nas dependências do campus Sete Lagoas. Na ocasião, a oficina foi ofertada apenas para a comunidade acadêmica, a fim de preparar os monitores para a reprodução da oficina com a comunidade externa (realizada durante o II Integrando, descrito adiante). A atividade, executada no hall do antigo prédio de aulas do campus, despertou a curiosidade de alunos e funcionários e resultou na produção de 23 bancos e duas mesas, que ficaram disponíveis no local para uso livre (Figura 2).

Figura 2 - Registros durante a oficina de móveis recicláveis: etapas da confecção de bancos de pneus e de mesas de carretel com mosaico em cerâmica.

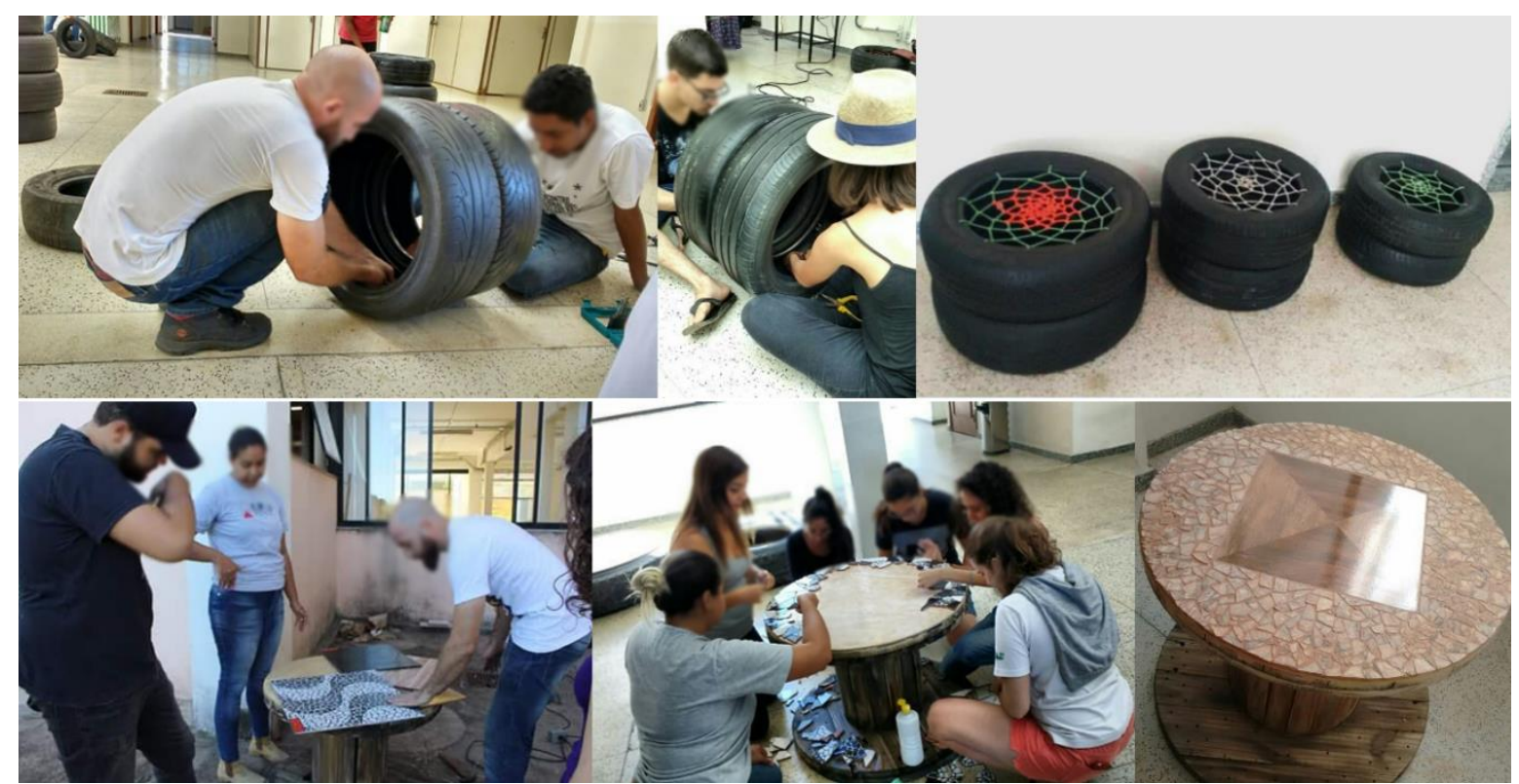

Fonte: arquivo pessoal.

Oficina de plantas suculentas e cactáceas

De acordo com Medina (2017), a educação ambiental pode desencadear um processo de transformação social em crianças com necessidades educativas especiais, como aquelas negligenciadas e/ou abandonadas por receberem maus-tratos, podendo apresentar condutas antissociais. Nesse sentido, foi planejada junto às lideranças comunitárias a realização de uma oficina sobre o cultivo de plantas em recipientes recicláveis, direcionada a crianças atendidas pela associação PLEC.

Revista Extensão em Foco, no 19, Jul./ Dez. (2019), p. 86 - 103. 
A atividade foi realizada no dia 30 de agosto de 2018, nas dependências do laboratório de Anatomia Vegetal da UFSJ-CSL, com a colaboração do professor Leonardo Dias, do Departamento de Ciências Exatas e Biológicas (DECEB). O professor foi responsável por ministrar o conteúdo teórico da oficina, de forma lúdica e didática, para 20 crianças e adolescentes residentes no Bairro Itapoã II, além de alguns pais e responsáveis que acompanharam as crianças até o campus.

Após os ensinamentos sobre o cultivo de plantas suculentas e cactáceas, membros do Programa Culturando atuaram como monitores da etapa prática da oficina, sendo responsáveis pelo levantamento dos materiais necessários para a confecção dos recipientes e pelo auxílio aos participantes na montagem e na decoração dos vasos de plantas. Durante a oficina, houve participação ativa de todos os presentes, sendo notório o aprendizado das crianças sobre a importância das plantas e as suas necessidades para permanecerem saudáveis (Figura 3).

Figura 3 - Registros durante e após a oficina de plantas suculentas e cactáceas.

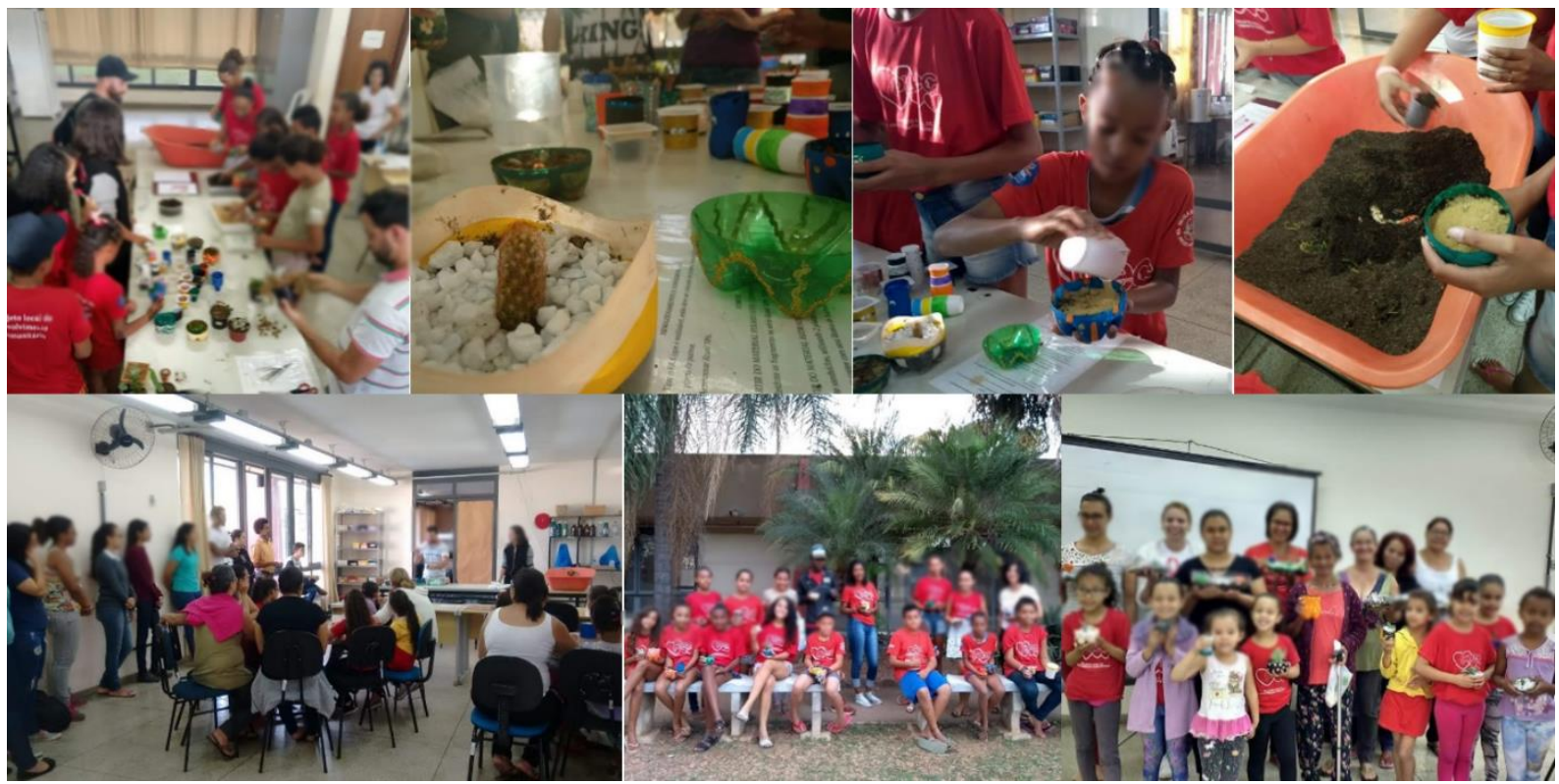

Fonte: arquivo pessoal.

\section{Grupo musical}

O instituto internacional The Arts Education Partnership (2016) relata em seu site oficial os benefícios da música no contexto acadêmico: "a música melhora a proficiência em matemática, leitura e desenvolvimento cognitivo, e aumenta habilidades para os alunos de segunda língua”. Em complemento, Areias (2016) afirma que a música é uma forma de

Revista Extensão em Foco, nº 19, Jul./ Dez. (2019), p. 86 - 103. 
expressão inerente ao ser humano e suscetível de partilha de emoções que favorecem a empatia e o prazer nas relações sociais.

Diante de todos esses benefícios, buscou-se estimular a população do bairro Itapoã II e a própria comunidade acadêmica a obter uma maior interação com a música, por meio de apresentações de um grupo musical formado por voluntários do Programa Culturando. O Grupo musical foi composto oficialmente por cinco integrantes, sendo três cantores, um violonista e um percursionista (cajón).

A escolha das canções foi realizada a partir de reuniões entre os integrantes do grupo, mesclando músicas de maior fama na atualidade com clássicos da música popular brasileira (MPB). Os ensaios foram realizados semanalmente, visando aperfeiçoar a sincronia do grupo e promover o estudo das letras das músicas. A primeira apresentação do grupo foi durante a abertura do XV Congresso de Produção Científica (02 de outubro de 2017) e a segunda, durante o evento I Integrando (01 de dezembro de 2017).

Em 2018, foram realizadas mais duas apresentações, em 25 de setembro de 2018, durante a feira agroecológica promovida semanalmente nas dependências do campus pelo grupo Guayi e a seguinte durante o II Integrando (30 de novembro de 2018). Em todas as apresentações, a participação do público mostrou-se muito expressiva nas músicas de maior fama na atualidade, evidenciando o envolvimento entre os espectadores e o grupo que se apresentava. Diante desse resultado, constatou-se que a música constituiu uma eficiente estratégia para favorecer a aproximação da Universidade com a Sociedade (Figura 4).

Figura 4 - Registros de ensaios e apresentações do Grupo Culturando em eventos dentro e fora do campus.

Revista Extensão em Foco, nº 19, Jul./ Dez. (2019), p. 86 - 103. 


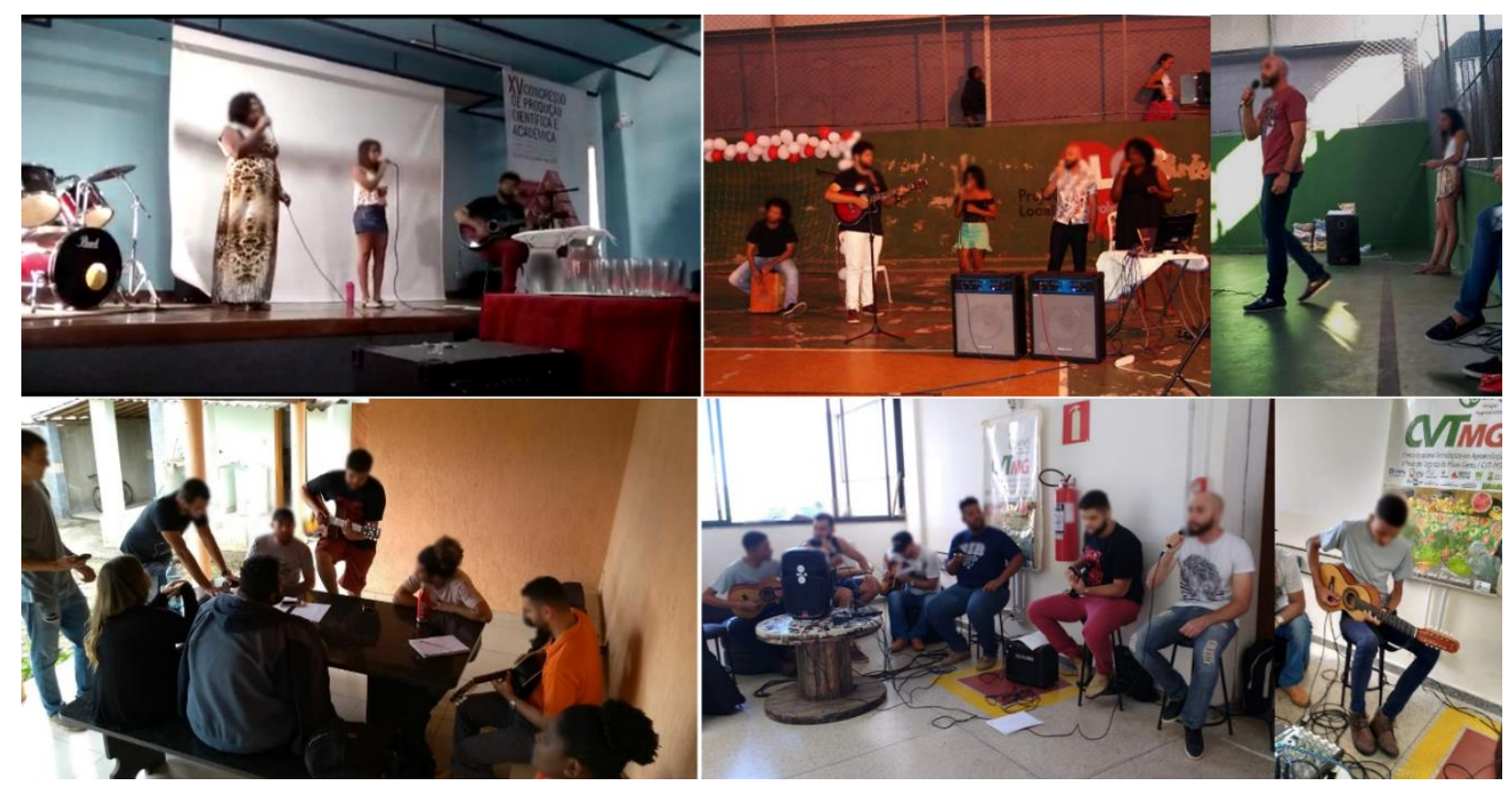

Fonte: arquivo pessoal.

\section{Integrando}

\section{Primeira edição}

O evento "Integrando" foi idealizado com o objetivo de gerar uma ação mais impactante na comunidade externa, a partir da realização de oficinas e minicursos de caráter artístico-cultural, educativo e de capacitação, concentrados em um evento de maior escala. A iniciativa foi viabilizada por meio de parcerias com outros projetos/grupos de Extensão atuantes no campus, a associação comunitária PLEC, empresas e cidadãos simpatizantes à causa, além do apoio individual de alguns docentes, discentes e funcionários da UFSJ-CSL.

A primeira edição do Integrando foi realizada ao longo do dia 01 de dezembro de 2017, com atividades executadas nas dependências do campus e da associação PLEC. O I Integrando abrangeu um "varal solidário", com a arrecadação de cerca de 900 itens de vestuário; oficinas direcionadas à comunidade (confecção de pipas, fabricação de detergentes, fabricação de balas de goma), dois campeonatos (tênis de mesa e xadrez), além do fornecimento de lanches, brinquedos e sorteio de brindes para a comunidade. A contabilização do público foi realizada por meio de assinatura em ata, sendo registradas 279 assinaturas de moradores no entorno da associação, mais a presença de 36 pessoas da comissão organizadora.

O dia de atividades foi encerrado com uma festa, com início às $18 \mathrm{~h}$ e término às $20 \mathrm{~h}$, realizada na quadra coberta da associação. A programação abrangeu cinco apresentações artísticas, incluindo grupos de dança do PLEC, sarau poético com crianças e três atrações Revista Extensão em Foco, no 19, Jul./ Dez. (2019), p. 86 - 103. 
musicais, dentre elas, o Grupo musical do Programa Culturando. Mesmo com a chuva forte, a festa contou com a presença de mais de 250 pessoas, correspondendo ao maior evento concentrado de Extensão já realizado pela UFSJ-CSL até a referida data (Figura 5).

Figura 5 - Registros das diversas atividades promovidas durante o I Integrando.

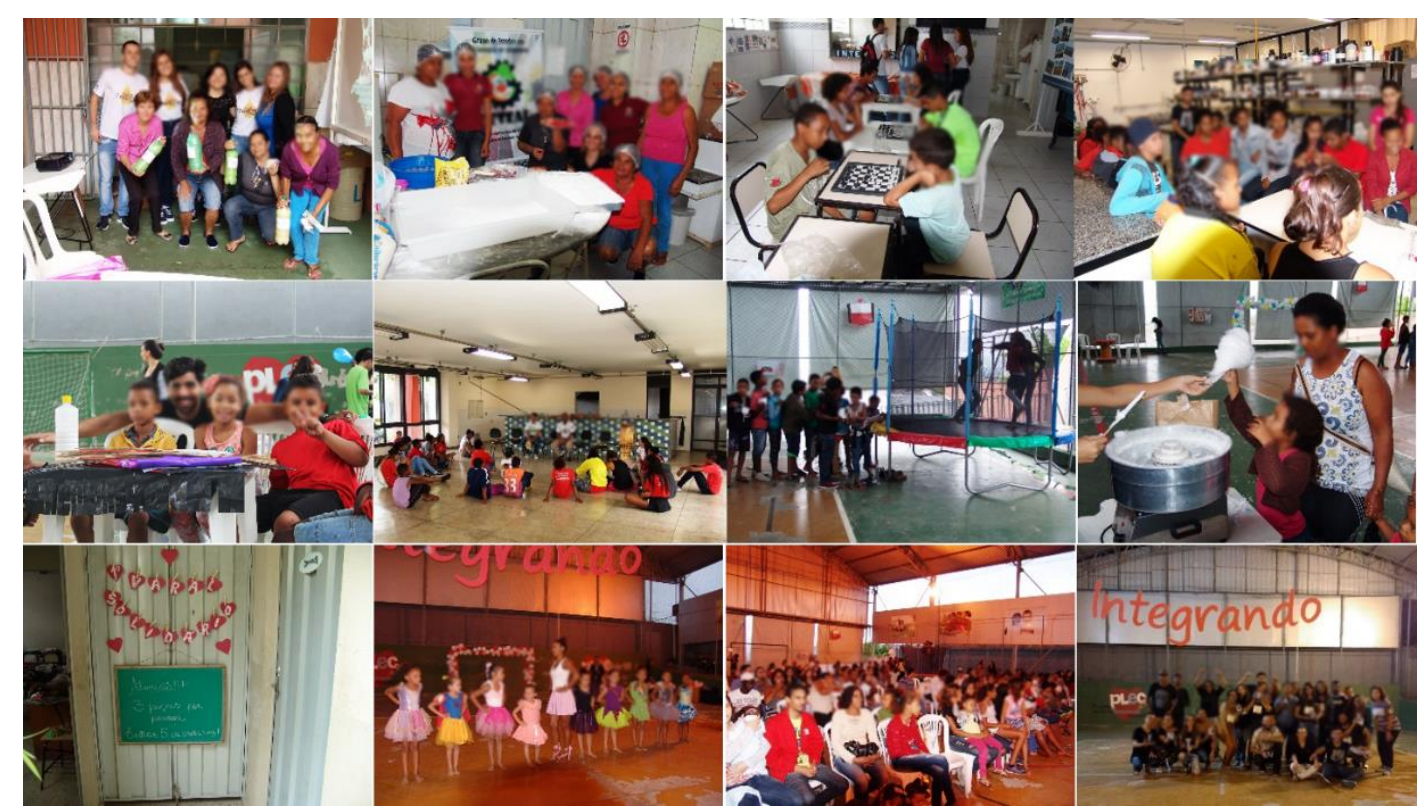

Fonte: arquivo pessoal.

Segunda edição

A segunda edição do Integrando (II Integrando) foi realizada ao longo dia 30 de novembro de 2018, nas dependências da associação PLEC. A programação do evento incluiu a realização de torneio de xadrez, oficina e minicurso de capacitação, Varal Solidário, distribuição de lanches e material escolar, sorteio de cestas básicas e uma festa de encerramento, com três apresentações de dança de alunas do PLEC e uma apresentação do Grupo musical do Programa Culturando. Foram registradas 400 assinaturas de moradores da comunidade no entorno da associação, o que representou um aumento de $30 \%$ em relação ao público atingido na primeira edição (Figura 6). Esse resultado consolidou esse evento enquanto ação extensionista de maior impacto da UFSJ-CSL. A seguir, são detalhadas mais informações a respeito das atividades realizadas durante o II Integrando.

Revista Extensão em Foco, no 19, Jul./ Dez. (2019), p. 86 - 103. 
Figura 6 - Registro de momentos diversos da segunda edição do evento Integrando.

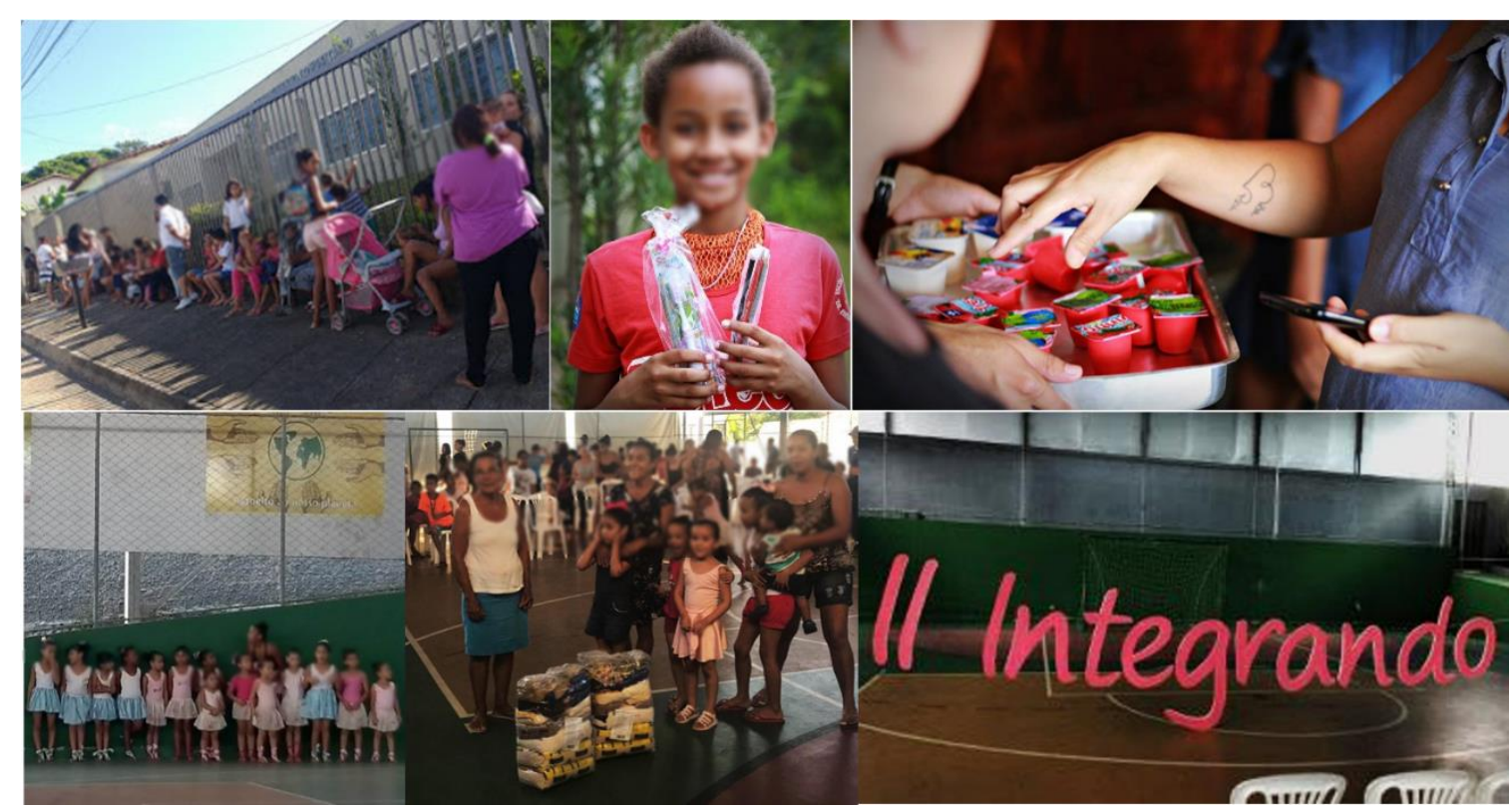

Fonte: Junio Souza Fotografias e arquivo pessoal.

Desde o segundo semestre de 2014, são ofertadas aulas de xadrez no PLEC, por meio de uma oficina do Programa Social de Desenvolvimento Local (PSDL). Diante da demanda de uma atividade competitiva para desafiar os alunos dessa oficina, um torneio de xadrez foi incluído na programação do II Integrando. O torneio foi realizado durante a manhã, sob a supervisão de dois voluntários do PSDL (Figura 7). Houve a participação de 12 crianças da comunidade, posteriormente premiadas com medalhas. Durante o torneio, foi possível observar que as crianças desenvolveram habilidades de raciocínio lógico, capacidade de análise, objetividade, autocontrole e auto avaliação, corroborando os benefícios da prática do xadrez citados por Santos e Melo (2016).

Revista Extensão em Foco, no 19, Jul./ Dez. (2019), p. 86 - 103. 
Figura 7 - Registros do torneio de xadrez realizado durante o II Integrando.

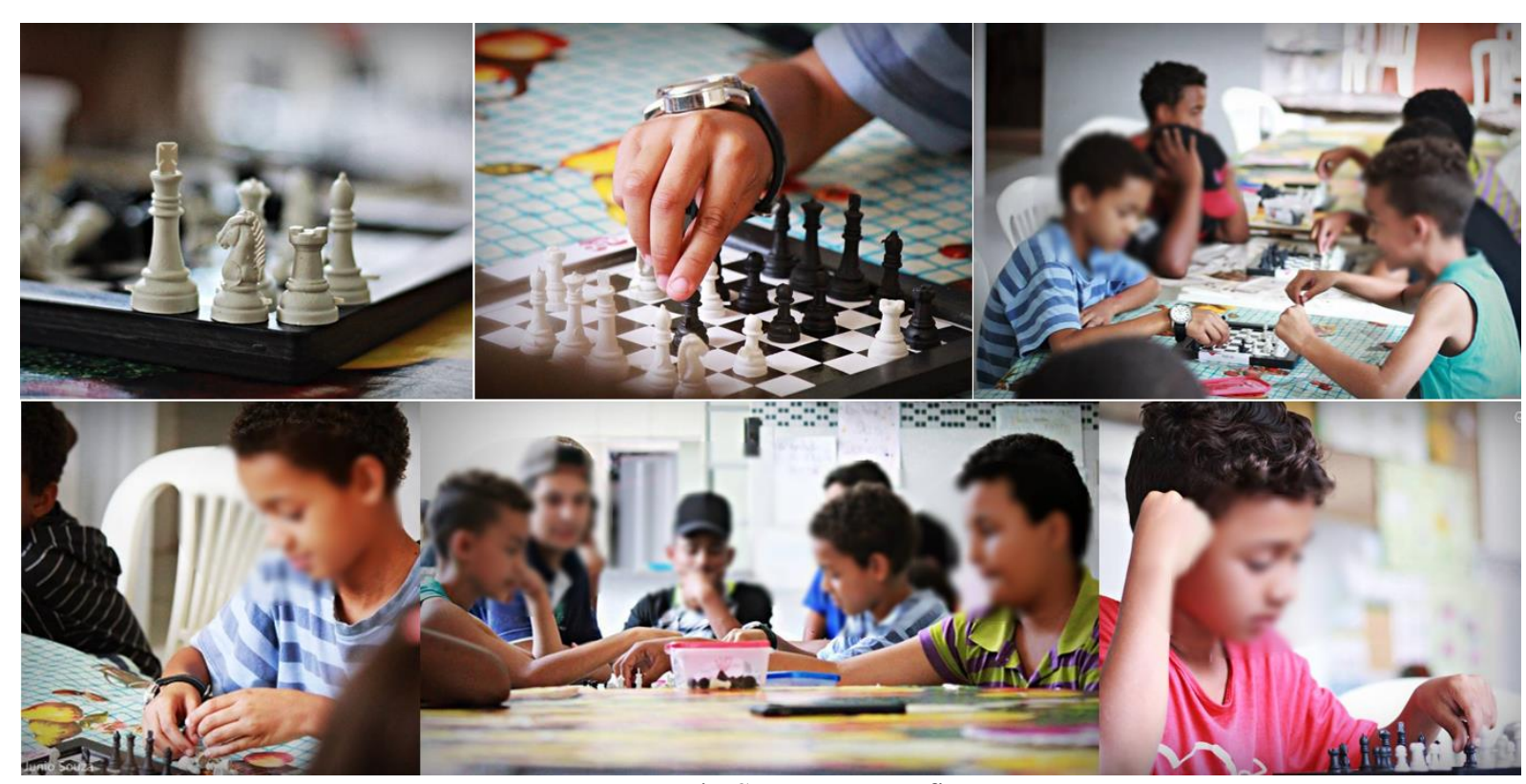

Fonte: Junio Souza Fotografias.

A partir da experiência positiva com a oficina de móveis recicláveis realizada na UFSJ-CSL (item I), parte da atividade foi reproduzida no PLEC durante o II Integrando. Foram arrecadados materiais suficientes para a produção de duas mesas de carretel. Houve a participação ativa de 15 crianças e adolescentes, que atuaram na colagem dos fragmentos de cerâmica e no acabamento final, sob a supervisão de membros do Programa Culturando. Após a oficina, as mesas produzidas ficaram disponíveis no PLEC para livre utilização (Figura 8).

Revista Extensão em Foco, no 19, Jul./ Dez. (2019), p. 86 - 103. 
Figura 8 - Registros da oficina de móveis recicláveis realizada durante o II Integrando.

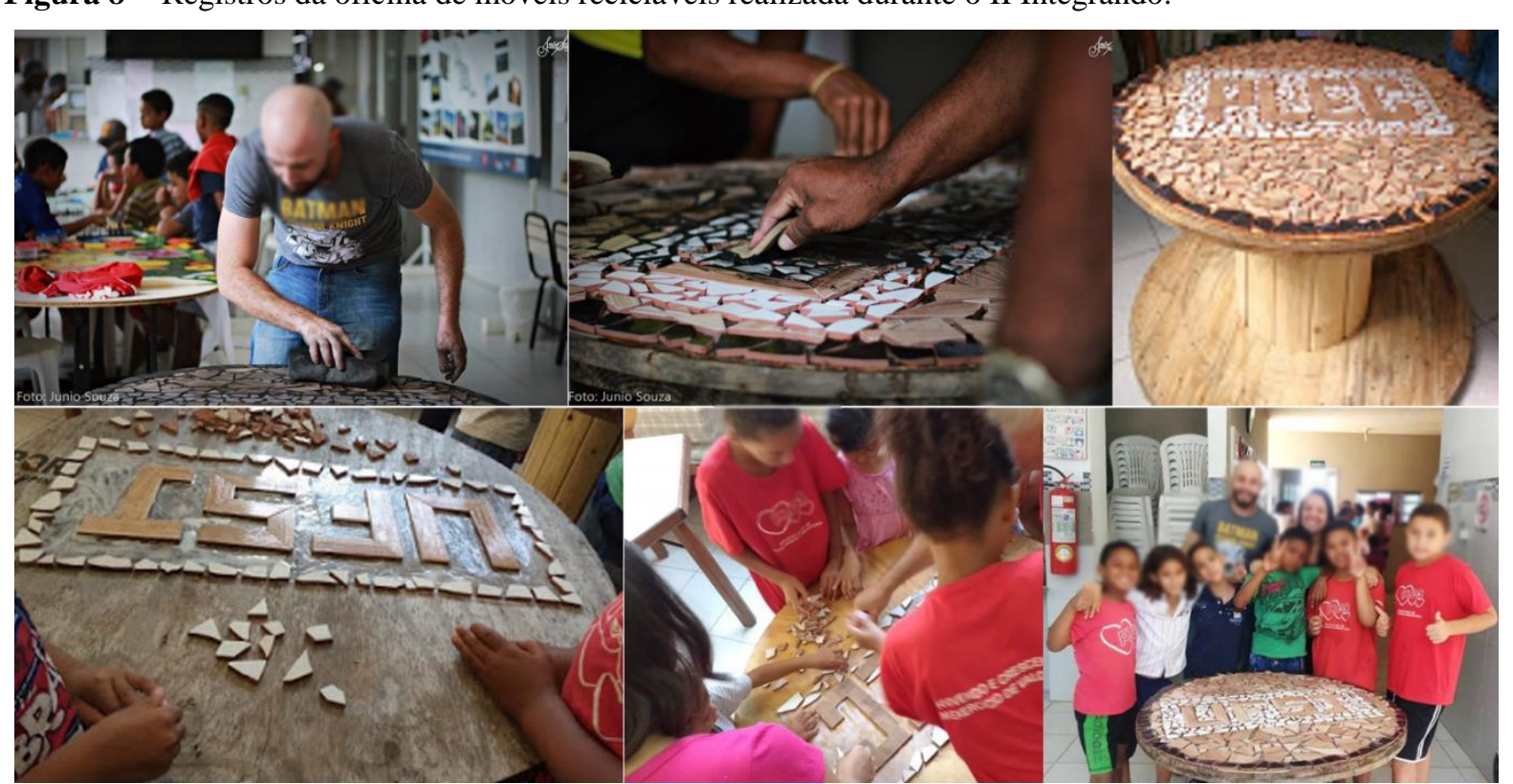

Fonte: Junio Souza Fotografias e arquivo pessoal.

No período da tarde, foi realizado um minicurso de fabricação de linguiça e hambúrguer artesanais, ministrada pelo professor Douglas Guimarães, docente do curso de Engenharia de Alimentos da UFSJ-CSL. A parte teórica do minicurso incluía informações sobre a seleção e o manuseio dos ingredientes, os cuidados sanitários e as principais técnicas de fabricação. A atividade foi direcionada a mulheres residentes no entorno do campus e em situação de fragilidade econômica. As 15 vagas oferecidas foram prontamente preenchidas e todas as participantes demonstraram grande entusiasmo e motivação durante a realização das atividades propostas (Figura 9).

Revista Extensão em Foco, no 19, Jul./ Dez. (2019), p. 86 - 103. 
Figura 9 - Registros do minicurso de fabricação de linguiça e hambúrguer artesanais do II Integrando.

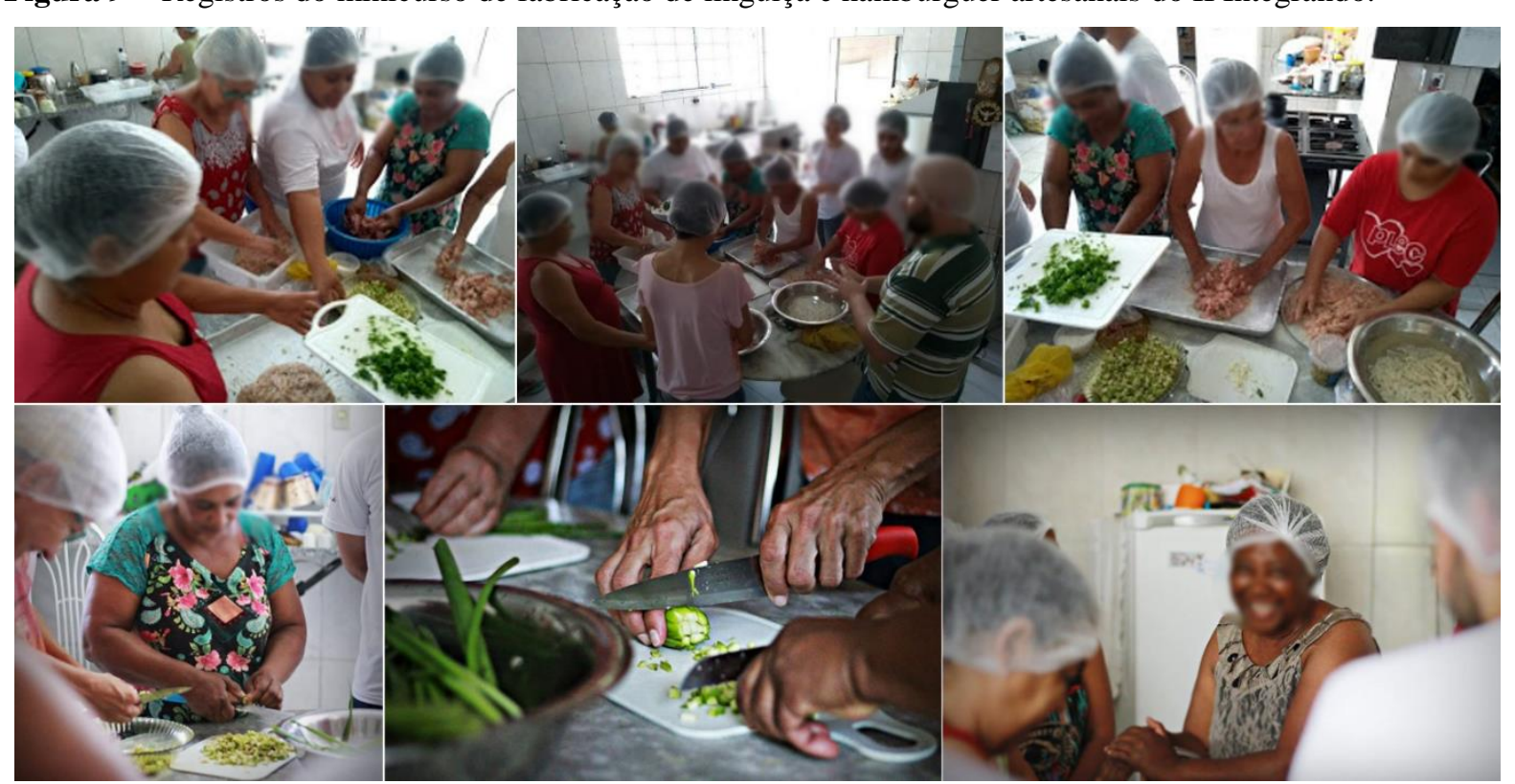

Fonte: Junio Souza Fotografias e arquivo pessoal.

O Varal Solidário foi uma das atividades mais aguardadas pelo público do II Integrando. A manutenção da parceria com as empresas locais apoiadoras da primeira edição foi mantida e ampliada, proporcionando mais de 17 pontos de coleta de doações espalhados pela cidade de Sete Lagoas. O Programa de Educação Tutorial do curso de Engenharia Agronômica da UFSJ-CSL (PET-Agronomia) também atuou como parceiro nessa atividade, auxiliando na implantação dos pontos de coleta, na seleção dos itens doados e no registro fotográfico do evento.

Na segunda edição, houve a arrecadação de mais de 1.500 peças de vestuário, além de dezenas de kits de material escolar e brinquedos. Com o sucesso de arrecadação, foi possível ampliar a oferta de três para cinco peças por pessoa, o que foi bastante celebrado pelos beneficiados (Figura 10).

No decorrer do evento, observou-se a grande importância da realização desse simples gesto que supre, ao menos em parte, a falta de atenção e de reconhecimento da sociedade em relação às demandas dessa população. Um relato semelhante sobre o impacto da realização de varais solidários em comunidades carentes foi reportado por Siqueira et al. (2016) em Cachoeira do Sul, RS, no contexto de um projeto de Extensão do curso de Enfermagem da Universidade Luterana do Brasil.

Revista Extensão em Foco, no 19, Jul./ Dez. (2019), p. 86 - 103. 
Figura 10 - Registros de momentos durante a segunda edição do Varal Solidário.

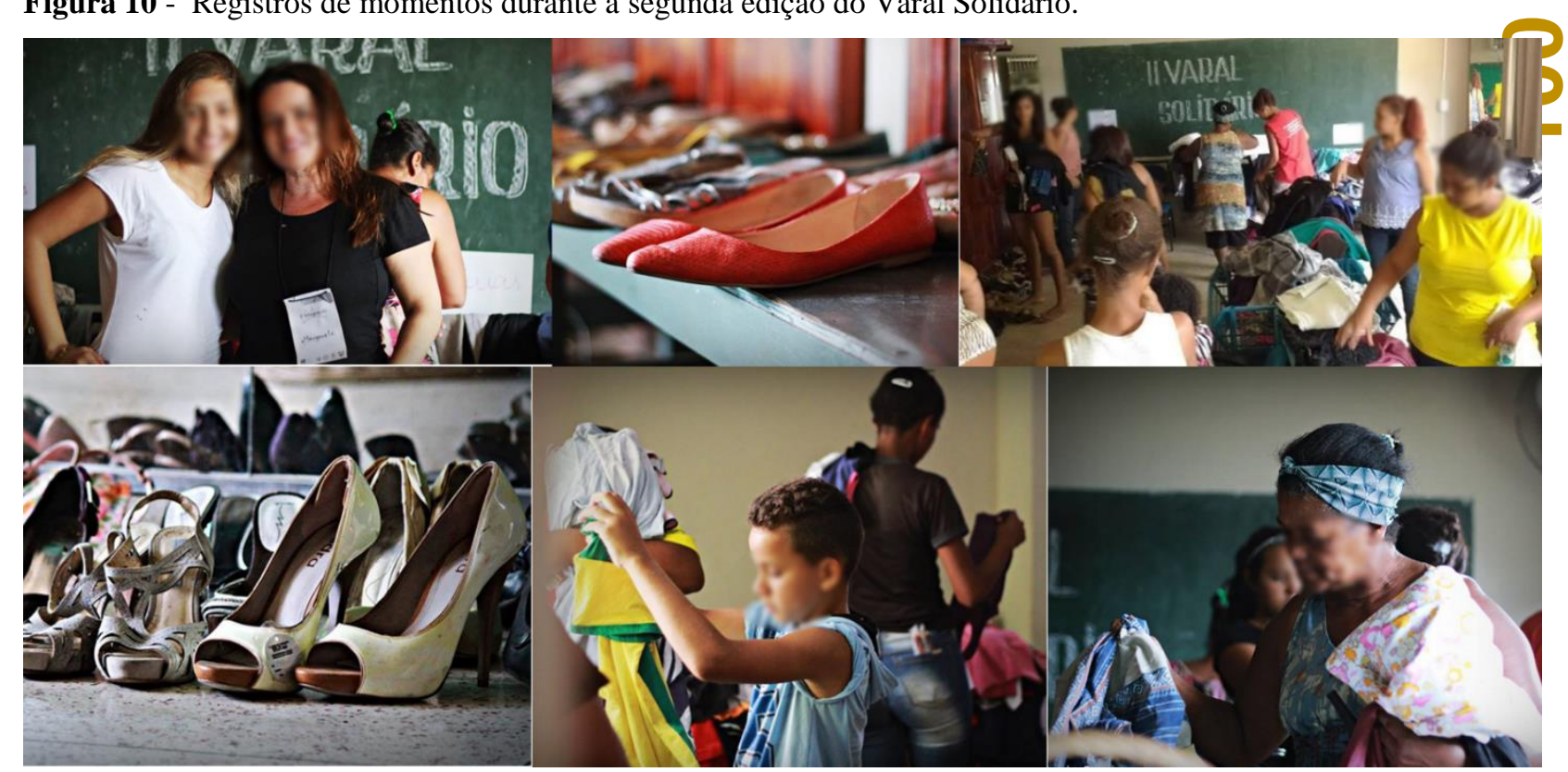

Fonte: Junio Souza Fotografias e arquivo pessoal.

\section{Participação em Congresso}

No período de 28 a 30 de junho de 2018, integrantes do Programa Culturando compareceram ao $8^{\circ}$ Congresso Brasileiro de Extensão Universitária ( $8^{\circ} \mathrm{CBEU}$ ), no município de Natal, RN. O evento foi realizado pela Universidade Federal do Rio Grande do Norte (UFRN), e reuniu professores, técnicos e alunos que promovem ações extensionistas no contexto das Universidades Brasileiras. A programação do $8^{\circ} \mathrm{CBEU}$ incluiu a realização de conferências, mesas-redondas, oficinas, comunicações orais e sessões de pôsteres.

A produção de trabalhos acadêmicos atuais sobre as ações do Programa Culturando foi amplamente estimulada, tendo em vista o enriquecimento intelectual e pessoal proporcionado aos membros do Programa que participaram da edição anterior ( $\left.7^{\circ} \mathrm{CBEU}\right)$, realizada em outubro de 2016 na cidade de Ouro Preto, MG. Na edição de 2018, foram apresentados três pôsteres, referentes ao Grupo musical e a atividades ofertadas durante o I Integrando (oficina de pipas e Varal Solidário) e um trabalho completo, na forma de comunicação oral. A participação no $8^{\circ} \mathrm{CBEU}$ foi fundamental para a divulgação em nível nacional das ações desempenhadas pelo Programa ao longo de 2017, permitindo uma nova troca de experiências e saberes no contexto da Extensão universitária (Figura 11).

Revista Extensão em Foco, no 19, Jul./ Dez. (2019), p. 86 - 103. 
Figura 11 - Participação do Programa Culturando no $8^{\circ}$ Congresso Brasileiro de Extensão Universitária.

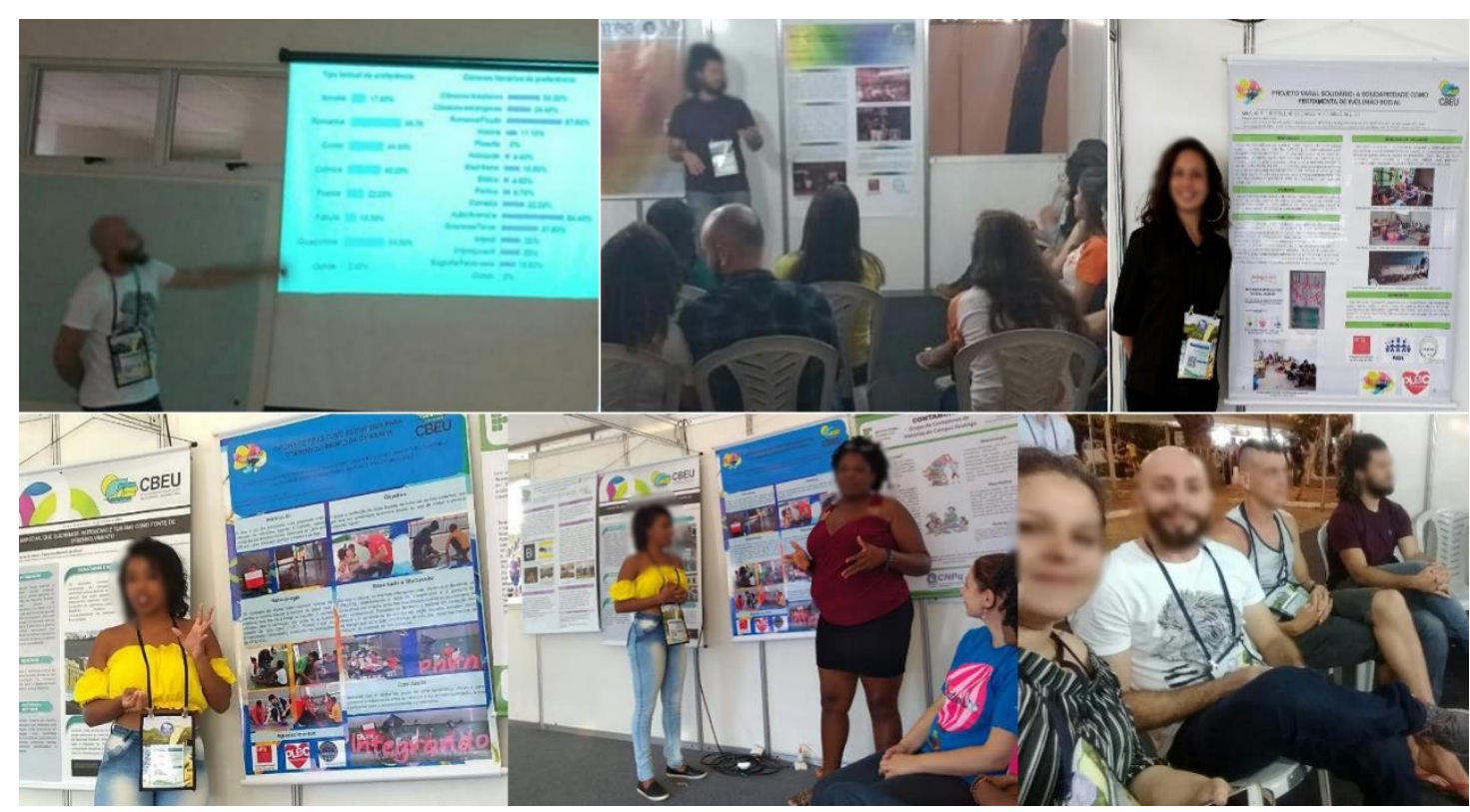

Fonte: arquivo pessoal.

\section{CONCLUSÕES}

Iniciativas pautadas pelo incentivo à Cultura, à Educação e à Capacitação profissional são alternativas viáveis para a aplicação bem-sucedida das diretrizes da Extensão universitária - Interação Dialógica, Interdisciplinaridade e Interprofissionalidade, Indissociabilidade Ensino-Pesquisa-Extensão, Impacto na Formação do Estudante e Impacto e Transformação Social, em contextos de vulnerabilidade econômica e exclusão social.

As ações do Programa Culturando possibilitaram uma efetiva aproximação entre a comunidade acadêmica da UFSJ-CSL e a comunidade em seu entorno, com a construção de uma ponte social entre Universidade e Sociedade. Por meio dessa ligação, são vivenciadas diferentes experiências, relações e interações sociais determinantes para a formação dos indivíduos e do coletivo, impulsionando a transformação da realidade sociocultural dentro e fora da Universidade.

\section{Agradecimentos e apoios}

À Universidade Federal de São João del-Rei (UFSJ), pelo suporte e auxílio financeiro, à Pró-reitoria de Extensão e Assuntos Comunitários da UFSJ (PROEX) e a todos os voluntários e parceiros do Programa Culturando pelo auxílio prestado.

Revista Extensão em Foco, no 19, Jul./ Dez. (2019), p. 86 - 103. 


\section{Referências Bibliográficas}

AREIAS, J. C. A música, a saúde e o bem-estar. Nascer e Crescer, v. 25, n. 1, p. 7-10, 2016.

BRANDÃO, C. R. O que é educação. São Paulo: Brasiliense, 2017. Coleção Primeiros Passos. 86p.

DIAS, G. F. Atividades interdisciplinares de educação ambiental. Global Editora e Distribuidora Ltda, 2015.

DIAS, L. S.; GUIMARÃES, R. B. (Org.) Desafios da saúde ambiental. Tupã: ANAP. Associação Amigos da Natureza da Alta Paulista. 2015. 176p.

FORPROEX. Fórum de Pró-reitores de Extensão das Universidades Públicas Brasileiras. Plano Nacional de Extensão Universitária. Manaus, 2012.

MEDINA, T. C. A. Educação ambiental: uma estratégia colaborativa para mudança do comportamento de crianças em risco social. Dissertação (Mestrado). Faculdade de Ciências Humanas e Sociais. Universidade Fernando Pessoa, 2017.

NUNES, A. L. P. F.; SILVA, M. B. C. A extensão universitária no ensino superior e a sociedade. Mal-Estar e Sociedade, v. 4, n. 7, p. 119-133, 2011.

PINHEIRO, D. C.; RIGUEIRO, J. C.; RODRIGUES, M. G.; MELO, M. A. Programa social de desenvolvimento local no entorno da UFSJ-campus Sete Lagoas. Revista Ciência em Extensão, v. 13, n. 2, p. 116-129, 2017.

SANTOS, A. M.; MELO, A. S A. S. Os Benefícios do Xadrez como Ferramenta Pedagógica Complementar no Processo de Ensino-Aprendizagem do Centro Educacional Vivência. Revista de Educação, v. 18, n. 25, 2016.

SANTOS, J. L. O que é cultura? São Paulo: Brasiliense, 2017. Coleção primeiros passos. 96p.

SILVA, J. B.; ZACARIAS, F.; GUIMARÃES, L. A. M. A universalização dos direitos sociais e sua relevância para o exercício e concreção da cidadania. Revista Estudos Institucionais, v. 4, n. 1, p. 308-333, 2018.

Revista Extensão em Foco, no 19, Jul./ Dez. (2019), p. 86 - 103. 
SIQUEIRA, N. S.; MACHADO, D.; BESKOW, M. Extensão no curso de enfermagem da ULBRA Cachoeira do Sul-uma aproximação com a comunidade. Anais do Seminário Internacional de Educação-SIEDUCA, v. 1, n. 1, 2016.

STRECK, D. R. Metodologias participativas de pesquisa e educação popular: reflexões sobre critérios de qualidade. Interface-Comunicação, Saúde, Educação, v. 20, p. 537-547, 2016.

THE ARTS EDUCATION PARTNERSHIP. Washington, 2016. Disponível em: <http://www.aep-arts.org/>. Acesso em Jan 2019.

UNESCO. Organização das Nações Unidas para a Educação, a Ciência e a Cultura. Acesso à cultura no Brasil. 2017. Disponível em: <http://www.unesco.org/new/pt/brasilia/ culture/culture-and-development/access-to-culture/>. Acesso em Fev 2019.

Revista Extensão em Foco, no 19, Jul./ Dez. (2019), p. 86 - 103. 
Revista Extensão em Foco, nº 19, Jul./ Dez. (2019), p. 86 - 103. 